\title{
Fraser Syndrome - A Case Report
}

\author{
BEGUM SHARIFUN NAHER
}

\section{Introduction:}

Fraser syndrome (Cryptophthalmos syndrome) is a rare autosomal recessive disorder. The most consistent features are cryptophthalmos, syndactyly of finger and toes, abnormal genitalia ${ }^{1}$. The first report of Fraser syndrome is attributed to Zehender and coworker $2,3,4$. In 1962 Fraser described the recurring constellation of cases of Cryptophthalmos with other congenital anomalies $^{5}$. The prevalence of Fraser syndrome FS has been established to be approximately forty three per 100,000 live birth and 11.06 per 100,000 still births ${ }^{6}$. We report the case of a full term newborn who had multiple abnormality consistent with Fraser syndrome cryptophthalmos. In addition the newborn had pulmonary stenosis which is a new finding in patients with this syndrome. To the best of our knowledge this is the first report of FS with cardiac lesion like pulmonary stenosis in a Bangladeshi newborn.

\section{Case report:}

A two hour old male newborn, $2^{\text {nd }}$ issue of her parents presented with inability to open eyes since birth and delayed cry. He had respiratory distress since birth. Mother Aleya was detected to have gestational diabetes in the last trimester but gives no history of Insulin to control it. Mother received homeopathic treatment in her $1^{\text {st }}$ trimester of pregnancy. There was no history of consanguinity of marriage. Baby was delivered by Lower uterine caesarean section at Mitford Hospital. On examination baby was found to be term weighing $4700 \mathrm{gm}$.

His both eyes seemed to be anophthalmic (Fig. 1). Baby was dysmorphic. Nose was small with hypoplastic nares and broad and depressed nasal bridge (Fig. 2). Syndactyly of $3^{\text {rd }}, 4^{\text {th }}$ and $5^{\text {th }}$ finger of both hands were present (Fig. 3). There was chordee (Fig. 4). Baby was tachypnic and $1^{\text {st }}$ and $2^{\text {nd }}$ heart sounds were normal. Systolic murmur was audible in the left $2^{\text {nd }}$ intercostal space. Occipitofrontal circumference was $37 \mathrm{~cm}$. Baby was provisionally diagnosed as Infant of diabetic mother (IDM) with mild perinatal asphyxia and multiple congenital anomaly.

Correspondence: Dr. Begum Sharifun Nahar, Associate Professor, Department of Neonatology, Sir Salimullah Medical College \& Mitford Hospital, Dhaka, E-mail: dr.sharifun_ nahar@yahoo.com

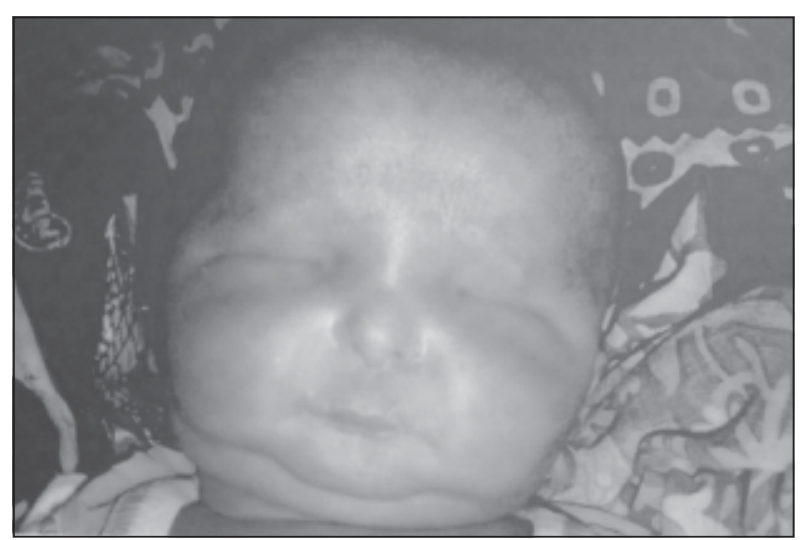

Fig.-1 : Cryptophthalmos (Hidden eye)

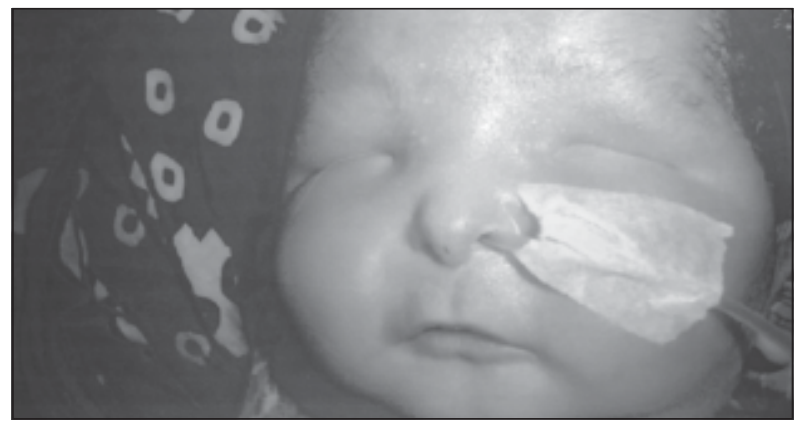

Fig.-2: Hypoplastic nare of nose with broad nasal bridege

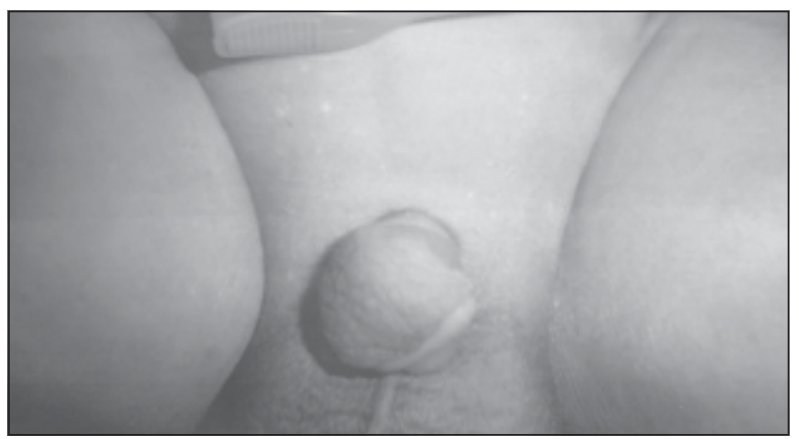

Fig.-3: Chordee of genitalia

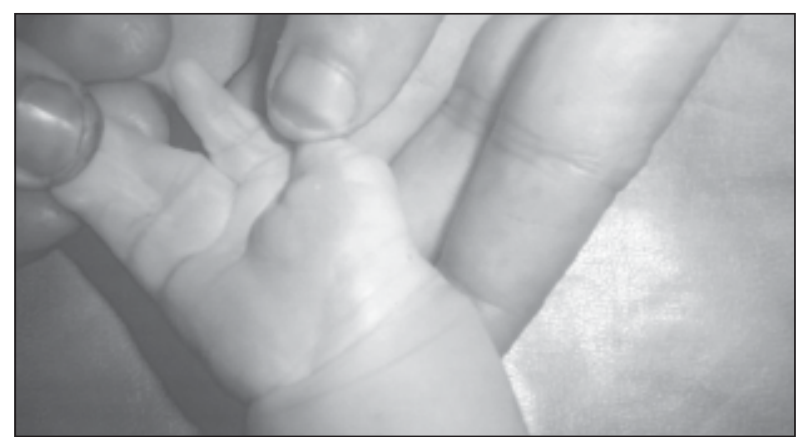

Fig.-4: Syndactyly of hand 
On investigation haemoglobin was $13.8 \mathrm{gm} / \mathrm{dl}$, TC of WBC was $16000 / \mathrm{cmm}$. DC of WBC was normal. Blood sugar was monitored according to protocol and it was within normal range. Blood for TORCH antibody showed positive IgG only. X- ray chest was normal but Doppler Echocardiography showed mild pulmonary stenosis. USG of brain and abdomen revealed no abnormality. Blood for karyotype was advised but parents could not afford it. Baby was referred to the department of Ophthalmology, Sir Salimullah Medical College Mitford Hospital and after examination the patient was found to have bilateral hidden eyes (cryptophthalmos) with no eye lashes. Baby was managed with protocolized treatment like IV fluid, O2 supplementation and antibiotic. Finally he was diagnosed as IDM, mild perinatal asphyxia and Fraser syndrome (FS). The diagnosis of FS was made in view of the presence of bilateral cryptophthalmos, syndactyly and genital abnormality with chordee.

\section{Discussion:}

FS is a rare disorder with more than 200 cases reported till date in the indexed literature. It combines acrofacial and urogenital malformation with cryptophthalmos. The findings in this case are compatible with the diagnosis of FS according to the diagnostics criteria proposed by Thomas et al $1986^{1}$. Two major and one minor criteria or one major and at least four minor criteria are needed for the diagnosis.

Diagnostic criteria of Fraser syndrome ${ }^{1}$

Major:

1. Cryptophthalmos

2. Syndactyly

3. Abnormal genitalia

4. Sibling with cryptophthalmos syndrome

Minor:

1. Congenital malformation of nose.

2. Congenital malformation of ears.

3. Congenital malformation of larynx.

4. Cleft lip or palate.

5. Skeletal defect

6. Umbilical hernia.

7. Renal agenesis.

8. Mental retardation.

In our case, there was cryptophthalmos, syndactyly and abnormal genitalia as major criteria and malformation of the nose as minor criteria. Cryptophthalmos is a leading feature of FS and has been described in $84 \%$ to $93 \%$ of the patients ${ }^{3,4}$.
Cryptophthalmos (hidden eye) fundamentally means absence of the palpebral fissure but usually includes varying absence of eye lashes and eyebrows and defects of eye. Syndactyly has been considered as a major feature of FS that occurs in $77 \%$ of the patients. Syndactyly is always cutaneous and in most cases involves fingers and toes ${ }^{3,4}$. Genital anomalies are cryptorchidism, micropenis, phimosis, chordee, hypospadius and scrotal hypoplasia in male ${ }^{3,4}$. In our case there was syndactyly in the fingers and micropenis with chordee in genitalia. Fraser syndrome is an autosomal recessive inherited syndrome. The parents of the affected children are sometimes but not always consanguineous. Consanguinity of marriage is reported in $15-24.8 \%$ of the cases ${ }^{3,4}$. It is notable that the parents of our case are not related. There is a recurrence risk of $25 \%$ among siblings of this syndrome ${ }^{7}$. Twenty five percent of affected fetuses are stillborn ${ }^{8}$ and mental retardation is seen in $80 \%$ of the survivors ${ }^{9}$. The clinically variable anomalies associated with Fraser syndrome support the genetic heterogeneity of the syndrome. The gene of the Fraser syndrome was located to $4 q 21$ FRASI gene ${ }^{10}$. Prenatal ultrasonography has been suggested to help in making the diagnosis of Fraser syndrome ${ }^{11,12}$. Findings of renal agenesis, orbital abnormalities, increased thoracic volume, oligohydromnios with voluminous hyper echogenic lungs and ambiguous genetalia should alert the sonologist towards the possibility of this syndrome in fetus. Genetic counseling should be based on high probability of recurrence, antenatal diagnosis in next pregnancy using ultrasonography and medical termination of pregnancy. Because the defect of eyelid development is frequently accompanied by ocular anomaly, the likelihood of achieving adequate visual perception is small, although early surgical intervention may have value. Twenty five percent of affected individuals are stillborn and an additional $20 \%$ die before 1 year of age. Death is related primarily to the renal or laryngeal defects.

\section{Conclusion:}

There is a great variation in possible malformation of Cryptophthalmos syndrome. So the diagnosis should be confirmed strictly adhering to the diagnostic criteria of Fraser or Cryptophthalmos syndrome.

\section{References:}

1. Thomas IT, Frias JL, Felix V. Isolated and syndromic Cryptophthalmos. Am j Med Genet 1986; 25: 85-98. 
2. Seal HM, Trabouls El, Gavaris P, SamangoSprouse CA, Parks M. Dominent syndrome with isolated Cryptophthalmos and ocular anomalies. Am J Med Genet 1992; 43: 785-88.

3. Ramsing $\mathrm{M}$, Rehder $\mathrm{H}$, Holgreve $\mathrm{W}$, Meinecke $P$, Lenz W. Fraser syndrome with Cryptophthalmos and syndactyly in the fetus and newborn. Clin Genet 1990; 37: 84-96.

4. Slavotinec AM, Tifft CJ. Fraser syndrome and Cryptophthalmos: A review of the diagnostic criteria and evidence for phenotypic modules in complex malformation syndrome. J Med Genet 2002; 39: 623-33.

5. Fraser GR. Our genetic load: A review of some of the aspects of genetic variation. Ann Hum Genet 1962; 25: 387-415.

6. Martinez- Frias ML, Bermizo Sanchez E, Felix $\checkmark$. Fraser syndrome frequency in our environment and clinical epidemiological aspects of consecutive series of cases. An ESP Pediatr 1998; 48: 634-38.
7. Berg C, Geipel A, Germer U. Prenatal detection of Fraser syndrome without cryptophthalmos: A case report and review of literature. Ultrasound Obstet Gynecol 2001; 18: 76-80.

8. Mahadevan B, Bhat BV, Sastri AT. Fraser syndrome with unusual features. A case report. J Anat Soc Idia 2002; 51: 59-60.

9. Ford GR. Irving RM. Jones NS. Baily CM. ENT manifestations of Fraser syndrome. J Laryngo Otol 1992; 106; 1-4.

10. Mc Gregor L, Makela V, Darling SM. Fraser syndrome and mouse blebbed phenotype caused by mutation in FRAS 1/ Fras 1 encoding a putative extracellular matrix protein. Nat Genet 2003; 34: 203-8.

11. Schuer GM, Dunn LK, Godmilow L, Eagle RC Jr, Knisley AC. Prenatal diagnosis and Fraser syndrome at 18 weeks of gestation, with autopsy findings at 19 weeks. Am J Med Genet 1990; 37: 583-91.

12. Fryns JP, Schoubroeck DV, Vanden Berche K. Diagnostic echographic findings in cryptophthalmos syndrome. Prenat- Diagn. 1997; 17: 582-84. 